\title{
10. Problems of bottom-up collaboration: evolutionary pathways and capacity challenges of NSMD governance certification institutions Benjamin Cashore ${ }^{1}$
}

\section{INTRODUCTION}

One of the most important issues for students of public policy and management in the global era is, as Kekez, Howlett, and Ramesh argue in the introductory chapter to this volume, to identify critical capacity gaps through which government officials might foster collaborative processes that help uncover complex instrument mixes for furthering, rather than exacerbating, identified policy goals. As Kekez, Howlett, and Ramesh note:

If these critical capacity deficits are not taken into account or pathways through which they might distort performance of collaboration are not considered then any short-term gain enjoyed by deploying a hybrid collaborative service delivery is likely to be cancelled out later when the consequences of policy failures and poor institutional design due to its governance limitations become apparent.

Drawing on Howlett and Ramesh (2016) they identify three overall capacity requirements, the importance of which varies across collaborative arrangements.

Political acumen capacity refers to individuals who are aware that a '... keen nose for politics not only within an organization but also the broader environment is essential for policy actors to be able to play an effective role in the policy process' (Howlett and Ramesh 2016: 306). This requires individual policy actors to develop a sound 'understanding of the key stakeholders, their key interests, and their strategies and resources' (Howlett and Ramesh 2016: 306). Policy analytical capacity focuses on the

skills [policy actors] possess for diagnosing problems and developing appropriate strategies for addressing them" including the ability to: (1) "acquire and use internal 
and external knowledge"; (2) "access and apply technical and scientific knowledge and analytical techniques"; and (3) "absorb and process information or evidence in recognizing, formulating, deciding, implementing, and evaluating policy. (Howlett and Ramesh 2016: 305)

Managerial expertise capacity emphasizes 'the ability to perform key managerial functions - such as planning, staffing, budgeting, and directing.' These technical skills are given much attention in management curriculum and include 'communication skills; leadership; teamwork; budgeting and financial management; decision making and problem solving; and ethics and integrity' (Howlett and Ramesh 2016: 305). Howlett and Ramesh emphasize leadership skills, as 'especially critical if groups are to assume new challenges and devise new strategies for meeting them' as well as those involving 'budgeting, accounting, and human resource management' (Howlett and Ramesh 2016: 305).

These capacity challenges as highlighted in Kekez, Howlett, and Ramesh's introduction, are key for realizing the potential of a range of collaborative governance approaches discussed in this volume including consultative in-house delivery; contracting-out; commissioning; co-management; and co-production, each of which have their own 'Achilles Heel' capacity challenge (see also Howlett and Ramesh 2016). Arguably no collaborative mode requires more careful attention to these capacity deficits, and pathways through which collaborative governance mechanisms must navigate, than the case of multi-stakeholder certification systems. This is because as modes of non-state market driven (NSMD) governance, policy actors are presented with an additional hurdle from other collaborative forms: that is, how to help build, rather than maintain, legitimacy and authority to govern (which requires political acumen capacity), and related, an ability to assess what types of problems, and associated historical processes, are best addressed and unleashed, through NSMD governance (which requires both political acumen and policy analytical capacity). These skills are important because, as we show below, they permit government officials to develop strategies that can help institutionalize legitimacy and authority which, once achieved, will change the impacts and problem-solving potential of the instrument or mix in question. Traveling such pathways requires that government officials undertake deliberate theoretical and conceptual thinking in which a number of possible futures are envisioned, rather than relying solely on backward looking evidence that biases analysts to (often poorly conceived) experiments 'already run.' This is important since as we review below, application of political acumen and policy analytical capacity reveals not one, but four 'problem solving' pathways (Cashore 2016; Cashore et al. 2012) through which certification systems might have influence. I argue that while the ability of government officials to travel any one of the 
four pathways requires political acumen and policy analytical capabilities, specific types of managerial capacities will vary somewhat depending upon which pathway is chosen.

Recognition of this leads to a modification of Howlett and Ramesh's (2016) 'Achilles Heel' argument by positing a hierarchical pecking order through which the three policy capacities must be applied if NSMD certification as collaborative governance is to realize its their potential. Political acumen must be first exercised, policy analytic must be second, and managerial while fundamental, must be applied subsequently. While this order is plausible based on historical evidence, we argue that the vast majority of skills held by government officials and non-governmental organizations seeking certification systems are not consistent with this pecking order. That is, managerial capacity has been prioritized which has undermined the analysis of historical trajectories, and much more complex arrangements, through which government officials can help nurture and navigate certification systems. This in turn, has led, at times, government and NSMD officials to overly rely on them to address too many public policy challenges which has, ironically, led to them underperforming (van der Ven and Cashore 2018). While lessons from this review can be applied to organizational and system levels (Howlett and Ramesh 2016: 304), I focus our attention on the types of political, policy and managerial capacities and capabilities required of individual government officials.

I elaborate these arguments in the following steps. First, I identify the key features of global certification systems that structure how collaborative governance pathways are to be discovered and collectively traveled. Second, I review how political acumen and policy analytic capacity are key for government officials if they are to uncover and influence, not one, but four potential pathways though which influence on public problem solving might occur. Third, I review the managerial capacities that government officials would need from the application of these higher-level capacity challenges, revealing how some are required regardless of the pathways, while others are unique to specific ones. I conclude by reflecting on how to fill and prioritize political and policy capacities gaps such that government managers can help nurture, rather than undermine, problem solving potential pathways. For clarity, I focus our collaborative certification example on efforts to regulate forestry as the most advanced case of NSMD globally.

\section{KEY STRUCTURAL FEATURES OF CERTIFICATION AS NON-STATE MARKET DRIVEN GOVERNANCE}

The origins of the first full-fledged NSMD governance system can be traced to the concerns of stakeholders around global forest degradation in the 1980s. Environmental groups, social activists, and even likeminded businesses 
were frustrated with the array of governmental, intergovernmental, and non-governmental initiatives that were designed to address deforestation and degradation and promote sustainable forest management. Environmental groups were concerned that the International Tropical Timber Organization's (ITTO) approach to promoting forest management practices and trade in the tropics simply created a 'logging charter' and were disappointed that the 1992 Rio Earth Summit (UNCED) (Bernstein and Cashore 2004; Humphreys 1996) failed to achieve a binding global forest convention. While many saw potential in tropical timber boycott campaigns, there was a recognition that these were short-lived, blunt, and often fostered conversion to less scrutinized crops.

\section{The Forest Stewardship Council Certification Solution}

The Forest Stewardship Council's (FSC) solution was to develop a broad mission to improve the management of the world's forests (Synnott 2005), which would house, and simultaneously promote, a range of social and environmental objectives. As a result, the broad coalition of environmental groups, social activists and business supporting FSC championed different issues including tropical forest loss and degradation, indigenous and forest dwellers' rights, and sustainable forest management generally (Rametsteiner and Simula 2003; Siry, Cubbage and Ahmed 2005). FSC's governance arrangements soon adopted a tripartite model that established three evenly weighted voting chambers: social, economic interests, and environmental. Votes in each chamber are weighted evenly between developing and developed countries. ${ }^{2}$ FSC mandates the establishment of national or regional initiatives, which are charged with drafting locally appropriate standards consistent with FSC's global Principles and Criteria $(\mathrm{P} \& \mathrm{C})$.

The FSC approach sparked a myriad of NSMD certification programs designed to address a range of problems from fisheries depletion, climate emissions, mining impacts, agriculture, coffee and tourism (Auld 2014; Auld et al. 2006; Auld et al. 2009; Auld and Cashore 2012a, 2012b; Auld, Renckens, and Cashore 2014; Bozzi et al. 2012; Kanie et al. 2013; see also Vince, Chapter 8 in this volume). Cashore (2002) identified (Table 10.1) five key features of NSMD certification systems that have been modified over the last two decades by Cashore, Auld and Newsom (2004), Bernstein and Cashore (2007), and Auld and Cashore (2012a). 
Table 10.1 NSMD governance: key features

\begin{tabular}{ll}
\hline $\begin{array}{l}\text { National/Global } \\
\text { Dimensions }\end{array}$ & $\begin{array}{l}\text { Policy standards (settings/specifications) must be consistent with global criteria } \\
\text { (objectives) and principles (goals) }\end{array}$ \\
\hline $\begin{array}{l}\text { Collaborative } \\
\text { Governance }\end{array}$ & $\begin{array}{l}\text { Government actors excluded (deemed ineffective as governing arena) } \\
\text { Business limited (must share equally with environmental and social interests) }\end{array}$ \\
\hline Practice: & Emphasis on clear 'on the ground' prescriptive requirements about specified \\
Rules & problems \\
\hline Practice: & Tend to be broad \\
Policy Scope & - Labour \\
& - Indigenous rights \\
& - Wide-ranging environmental impact \\
\hline Authority: & Emergence Phase: consequentialist (market incentives for those being certified) \\
& Entrenchment Phase: appropriateness (political legitimacy) \\
\hline
\end{tabular}

Source: Adapted from Cashore (2002) and Auld and Cashore (2012a, 2012b).

\section{DIRECT AND INDIRECT EVOLUTIONARY PATHWAYS: POLITICAL ACUMEN AND POLICY ANALYTIC CAPACITIES}

The first task facing government officials who seek to draw on collaborative governance to address problems, usually the domain of government actors, is to identify how to improve support in the marketplace for certification systems - be it in the form of consumer 'willingness to pay' to decisions by firms along global value chains, often owing to NGO targeting campaigns - to reward, and provide benefits to producers who agree to abide by the private regulations. Such exercises require a high degree of political acumen capacity because officials must be able to assess the broader context in which certification as collaborative governance has emerged. This includes an ability to understand the historical role of different stakeholders, power dynamics, and problem definitions they seek to nurture, from environmental challenges such as endangered species and biodiversity conservation, to the economic role of forests for improving the plight of impoverished peoples. Political acumen capacity is also key for understanding not just geo-politics, but the contribution of different explanatory frameworks for observed support and opposition, as they are key for identifying future courses of action (Bernstein et al. 2000), including triggering shifts in motivations over time.

At the same time, policy analytic capacity is fundamental, since collaborative certification systems do not just build new global institutions governing through the marketplace, they also attempt to address specified problems that expand on traditional regulatory approaches (Auld 2014; Auld et al. 2009; Auld, Cashore and Renckens 2014) by assessing how standards might nurture, 
Table 10.2 Individual policy capacity requirements for identifying and traveling causal pathways: cross cutting

\begin{tabular}{ll}
\hline Type & Training \\
\hline Political & $\begin{array}{l}\text { Sophisticated social science training in international relations, economics, sociology, } \\
\text { organizational and institutional analysis that emphasizes norm change, historical } \\
\text { trajectories, and transformative triggers. }\end{array}$ \\
Policy Analytical & $\begin{array}{l}\text { Domestic, comparative and international policy process, policy sciences, stakeholder } \\
\text { coalition building including role of policy learning mechanisms, internal and external } \\
\text { perturbations. }\end{array}$ \\
& $\begin{array}{l}\text { Excellent communications, budgeting, leadership and team building skills, cost-benefit } \\
\text { analysis. }\end{array}$ \\
\hline
\end{tabular}

rather than straitjacket (Greening and Gray 1994), collaborative governance potential. Policy analytic capacity is also required for reflecting on how technical/managerial decisions can be linked to, rather than undermine, the broader project of building legitimacy and authority (Auld et al. 2010).

Looking over 25 years of research and practice, the role of political acumen and policy analytic capacity were fundamental in uncovering pathways in which norms and preferences changed in response to strategic interventions. These capacities were key in conceptualizing not one, but four evolutionary pathways through which impact might occur. Where these capacities were absent, government officials and strategists often undertook well intended efforts that stymied their potential. Hence, policy actors capable of intervening, and reflecting on future impacts, tend to have the political acumen capacity that comes from training in historical institutionalism (Thelen 2003) and comparative historical sociology (Mahoney 2008), in ways that complement, rather than are subordinated by, those fields that emphasize backward looking 'evidence based' (Sanderson 2002) and 'data driven,' analysis that, taken in isolation, ironically, reinforced the priority of managerial capacity.

\section{Direct Pathway}

The direct pathway is the one that the vast majority of scholarly and practitioner work on NSMD political acumen and policy analytic attention has been placed. Scholars that emphasize an evolutionary approach, including my own collaborative work, have posited that if NSMD systems gain authority to directly create policy through which most businesses adhere, strategists must confront a conundrum inherent in the design of the system: the higher the standards initially, the lower the support and only modest impacts could be expected; conversely, the lower the standards, the higher the support but also only modest impacts would accrue (Cashore et al. 2007a). 
Table 10.3 The dilemma of high and low certification requirements, time 1

\begin{tabular}{lll}
\hline & \multicolumn{2}{l}{ Requirements of certification systems } \\
\cline { 2 - 3 } & High & Low \\
\hline Level of Firm Support & Low & High \\
Impacts on Sustainability & Low & Low \\
\hline
\end{tabular}

Source: Cashore et al. (2007a).

In other words, practitioners with these types of capacity skills have spent a great deal of time, as have researchers, on identifying how these 'causal influence logics' might help foster coherent choices by businesses, environmental groups and social activists - and even governments - and might, through nurturing collaborative governance arrangements, ultimately achieve 'high support, high standards and high impacts' (Bernstein and Cashore 2007). The strategic implications that emerge from application of policy analytic capacity are profound: supporters must develop certification standards that are high enough to be meaningful for addressing an 'on the ground challenge,' but at a level that rewards existing 'top producers,' who are often practicing at a high level owing to government regulations. Application of this lens has practical significance in understanding historical efforts that both applied, and did not apply, these policy acumen insights. For example, a generation ago well-intended environmental activists worked to increase FSC standards in British Columbia Canada (Cashore, Auld and Newsom 2004), following widespread interest on the part of most industrial players to support FSC. However, these activists failed to analyze carefully why firms were supporting FSC — which was largely owing to increases in government-initiated regulations. Therefore, the change logic was not that support for the FSC would enhance domestic forest practices in highly regulated jurisdictions, but rather, in drawing on support from firms operating in these settings, greater market signals might be generated to target the behavior of firms operating in less regulated jurisdictions. However, lack of capacity to apply this type of thinking resulted in most $\mathrm{BC}$ firms vacating original support, and turning to the much less prescriptive industry standard. Similar results also occurred in the Canadian Maritimes (Cashore and Lawson 2003) and Finland (Cashore et al. 2007b) FSC standard setting processes. Following these institutional and policy failures, FSC and its supporters began to fill political acumen and policy analytical capacity gaps, which led to strategies to foster standard setting processes elsewhere in Canada in the boreal forests (Auld 2006), more consistent with the governmental regulation 'as spark' trajectory. During these unfolding historical processes, public managers with policy and analytic capacity were 
Table 10.4 NSMD direct pathway

\begin{tabular}{ll}
\hline Causal Influence Logic & Strategic Implications \\
\hline Must achieve strong support among & - Strategists must gain support from most producers to be \\
purchasers along transnational supply & effective \\
chains & - Standards should be set to reward, not punish, firms that are \\
& already highly regulated \\
& - Increases in standards must follow, not precede, enhanced \\
& market uptake \\
\hline
\end{tabular}

best positioned to nurture collaborative certification systems that fostered public agendas. For instance, those seeking to draw on certification to foster domestic sustainable forest management goals could envision the efficiency and international credibility gains for supporting these efforts, such as certification friendly procurement policies, to providing resources for fostering collaborative certification dialogues (Cashore 2002: 510), rather than viewing them solely as a threat to state sovereignty.

Application of this type of political and policy acumen capacity led a number of scholars and practitioners to reflect on the ways in which collaborative governance that includes highly different motivations among business, environmental and social activists, might shift eventually towards collective norms about the appropriateness of the institutional arena (Bernstein and Cashore 2007). These efforts have been taken up by integrating Bernstein and Cashore's work on international pathways with a focus on policy learning regarding strategy and institutional formation (Cashore et al. 2016a; Cashore et al. 2016b; Humphreys et al. 2017).

For all these reasons it is clear that if government officials are to draw on, and help nurture, collaborative certification governance to address public policy problems, they need political acumen skills that emerge from training in political science, sociology, anthropology, history or related disciplines that emphasized deep conceptual and theoretical analytical skills on questions of power, legitimacy, authority and political legitimacy. Likewise policy analytic capacity is required to help shape strategic choices capable of understanding why low standard eco-labeling competitors emerge, and implications for 'ratcheting up' standards over time. These skills must include an ability to respond in ways that incorporates differences across certification systems without alienating most stakeholders.

\section{Superseding Pathway}

The superseding pathway was identified through political and policy analytic capacities by identifying the role of collaborative certification in creating a 
Table $10.5 \quad$ Superseding $=$ creating a learning laboratory

\begin{tabular}{ll}
\hline Causal Influence Logic & Strategic Implications \\
\hline Governments adopt NSMD standards for & - Only attract top producers to trigger diffusion to government \\
mimetic, normative or learning processes & regulations \\
& - Certification standards should be maintained at the highest \\
& of levels \\
\hline
\end{tabular}

'learning laboratory' in the hopes that through diffusion and isomorphism, governments and other actors may decide to adopt these practices (Cashore, Matas et al. 2012). Unlike the direct pathway, this indirect one requires significant attention and support from government officials, since they will ultimately be developing the (diffused) regulations. Scholars and practitioners have envisioned this role as potentially the most effective for such NSMD systems as LEED Green Building certification who tend to obtain direct support from a narrow set of institutional building owners, rather than everyday home-owners. Hence, the process for broader impact is the diffusion of these standards into municipal building codes and related regulations.

The strategic implications for this 'superseding' pathway that aims to gradually inform policy are different from the direct approach. In particular, strategists should attempt to generate and maintain 'high standards' because it is through diffusion to government policies that the biggest impact can be achieved. Unlike direct pathways, decisions to lower standards to gain increased membership are misplaced-because it is learning about best practices, rather than generating widespread support, that leads to indirect influence through impacts on public policies. In addition, officials from key government regulatory agencies play a key role, and must constantly maintain open channels of communication with officials from certification programs while maintaining institutional autonomy.

Key individual policy capacity requirement dynamics include political acumen skills capable of understanding, and promoting, policy diffusion from private governance institutions to traditional governmental processes. This requires an ability to understand existing norms within policy subsystem dynamics, but also how, by engaging governmental arenas through policy diffusion processes, norms and discourses might change over time (Dobbin, Simmons and Garrett 2007). Likewise policy analytic capacity is key, as this requires understanding, and managing, diverse stakeholders on the one hand, as well as the nuances of public policy process, on the other hand. Policy analytic skills must also include an ability to master nuances of a specific and complicated policy field that incorporates knowledge from a range of social, biological, and physical sciences. 


\begin{tabular}{ll}
\hline Causal Influence Logic & Strategic Implications \\
\hline NSMD system fills gap in public policy & - Government officials can draw on NSMD standards to fill \\
approach, reinforcing legitimacy of each & gaps in existing public policy instruments \\
other & - Government and certification officials should avoid \\
& duplication with the other \\
\hline
\end{tabular}

\section{Symbiotic Pathway}

A third pathway captures cases in which NSMD systems emerge to address a gap in international agreements or public policies. For example, when environmental and social activists were concerned that the Kyoto Protocol's 'Clean Development Mechanism' (CDM) downplayed non-carbon concerns, such as equity and biodiversity, they did not want to 'open up' hard-won deliberations for fear they might reduce, rather than increase, existing protections. As a result, some activists turned and championed the CDM 'gold standard' certification program as a way to fill gaps, encouraging those engaging in CDM activities (Levin, Cashore and Koppell 2009). In these cases, government officials must have the capacity to recognize that public regulation and the NSMD certification system are symbiotic, each reinforcing the other. This means that government officials can, quite innovatively, draw on certification systems to fill gaps in public policy, rather than seeking changes in their own hard fought efforts which could cause duplication and undermine support.

To do this well, policy analytical skills are also required, including intensive training in international relations and global governance, especially those bodies of research that are targeted towards understanding why states cooperate, and implications for compliance and effectiveness. These skills are usually taught in departments of international relations and global affairs.

\section{Hybrid Pathway}

A fourth pathway that emerges from an application of political acumen and policy analytic capacities fits under the broad category of 'hybrid' governance. This category most closely conforms to the collaborative governance discussion in Kekez, Howlett, and Ramesh's introductory chapter in that it also focuses, ultimately, on how certification might help foster changes within both private and public policy by emphasizing policy mixes that might provide innovative solutions. These mixes, and the different levels of policy interventions, have been disentangled by Cashore and Howlett (2004; Howlett 2009), building on Hall (1993), Sabatier and Jenkins-Smith (1993) and others 
Table 10.7 Key features of legality verification

\begin{tabular}{ll}
\hline Role of Governments & Sovereignty reinforced, not challenged \\
\hline Policy Scope & Relatively modest \\
\hline Assurance & Third party verification \\
\hline Role of Markets & Tracking along product supply chains \\
\hline
\end{tabular}

Source: Cashore and Stone (2012), drawing on Cashore, Auld and Newsom $(2002,2004)$ and Bernstein and Cashore (2007).

who, advancing policy analytic capacity, identify six different policy cells that officials might draw on to nurture influence. The ability to identify whether private or public policy is best for each cell, and the potential of developing mixes across the cells, for shaping impacts over time requires the integration of political acumen and policy analytic capacity skills.

To be sure, application of these skills to advance certification through hybrid interactions with public policy can yield literally thousands of possibilities each with their own 'causal influence logic' for addressing public policy problems. This means that the only way to identify specific skills that would be required of individuals is to 'work backward' from a specific innovation. To illustrate the potential of hybrid governance, and the priority of political acumen and policy analytic capacity, we reflect on our work on the case of legal verification of global value chains to which so many policy actors and scholars have devoted so much attention in the last 10 years.

\section{Conceptualizing legality verification (LV)}

The idea of verifying whether production and manufacturing of consumer goods have followed the laws of the countries of origin has gained increasing interest by those championing improved apparel manufacturing facilities, and extractive processes within mining, fisheries, and oil and gas production. Within forestry such an interest has coalesced by those seeking to combat 'illegal logging': that is, failure to comply with laws and regulations developed by government officials such as illegal conversion of forests to other agriculture crops (deforestation); and logging that ignores environmental and social regulations (Cashore and Stone 2012, 2014).

Like NSMD systems, LV's mechanism for weeding out illegal logging is to track legal wood along global supply chains that cut across multiple jurisdictions. Likewise, third party auditing, rather than relying on traditional enforcement agencies, is emerging as a key mechanism to assure legal compliance. However, unlike certification, these efforts seek to improve government capacity to enforce their own laws (Hyde 2009). 
For these reasons it is imperative that government officials have the political and analytic skills to distinguish LV from certification, since the former can help governments through collaborative governance in ways that reward, rather than constrain, legal producers. It is precisely for these reasons that so many government officials in developing and developed countries are supporting the removal of illegal products along global value chains to improve domestic governing capacity.

\section{Theorizing LV's emergence and evolution: strategic implications}

Just how to research, and assess, a dynamic policy instrument such as LV that operates across multiple levels of governance requires applying both political acumen and policy analytic capacity such that theoretical and empirical analysis can be integrated to uncover plausible 'causal influence logics.' Drawing on a range of empirical case studies in Brazil, the United States, the European Union, China, Malaysia, Cameroon, and Indonesia (Cashore et al. 2016a), and theoretical work reviewed above, scholars applying political acumen and policy analytic skills have conceptualized two phases, with distinct 'causal influence logics' through which policy actors might nurture and entrench LV (Cashore and Stone 2014).

During Phase I, support occurs only when a range of government, business and environmental groups all come to recognize some type of strategic organizational interest in supporting efforts to 'weed out' illegal logging from supply chains. Drawing on policy acumen capacity, Cashore and Stone (2014) theorize that law abiding businesses will support LV as a policy instrument when they evaluate current or potential economic rents associated with weeding out illegal supply (which should drive up prices, at least in the short term) and market access, as being higher than the costs of support (that they incur through standards, auditing processes, and supply chain tracking of legal wood). Hence policy analytic capacity is fundamental for identifying and building supply chain tracking systems capable of weeding out illegal wood as fundamental for Phase I, requiring that government officials focus attention on developing stakeholder engagement that maintains coalitions of businesses and environmental groups. Cashore and Stone (2014) theorize that a second phase of LV, with different logics, allows for regulatory expansion once LV of the entire supply chain is institutionalized such that shirking among consumers and/or producers is considered normatively unacceptable. In this case, government officials must have the conceptual skills to identify phase II, since it can only be measured after their efforts are unleashed and the managerial skills/ training from economics to know that when such conditions exist, increases in regulations will impose costs on consumers, rather than firms (Cashore and Stone 2012, 2014). 
Table 10.8 Hybrid pathway for reinforcing compliance to government standards

\begin{tabular}{ll}
\hline Causal Influence Logic & Strategic Implications \\
\hline Influence depends on the specific hybrid & - Government officials must draw on transnational LV to \\
in question. NSMD 'look-alikes' have & 'weed out the worst,' rather than rewarding the top \\
emerged that reinforce government & - Government officials must first focus on collaborative \\
policies, rather than private standards & governance around supply chain tracking \\
& - Government officials must identify a plan for phase 2 in \\
& order to maintain multi-stakeholder collaborative governance \\
& beyond business interests \\
\hline
\end{tabular}

Application of a high degree of political acumen and policy analytic capacity among government officials in China, the US and Indonesia help explain why there was a flip from lukewarm or nonexistent support in the early 2000s to strong support by the late 2000s (Cashore and Stone 2014). Likewise, these skills allow policy actors to disentangle the type of policy problems LV could address, such as promoting responsible extractive practices, from more thorny policy problems, such as conserving biodiversity over extractive interests.

\section{DIRECT AND INDIRECT EVOLUTIONARY PATHWAYS: MANAGERIAL CAPACITY REQUIREMENTS}

Given this review has identified critical political acumen and policy analytic capacity that cut across, and help the identification of four distinct causal pathways, what then are the managerial requirements of policy actors who seek to influence them? We can identify skills, drawing on Howlett and Ramesh (2016), which like political acumen and policy analytic capacities, cut across all four pathways: excellent communications, budgeting, leadership and team building skills, and ability to conduct a range of cost-benefit analysis calculations, from optimization efforts to multi-goal policy analysis. These skills are taught in public administration and public policy schools. In addition, as NSMD systems follow business principles as much as government bureaucracies, managers ought to be aware of, and trained in management techniques discovered, and applied, by key business management scholars such as Peter Drucker (2001) who teaches how a 'knowledge worker' leader can generate learning by empowering employees to realize organizational objectives through decentralized arrangements and collaborative learning (Senge 1990). Mintzberg and McHugh's (1985) findings about the way in which leaders can foster organizational coherence allows leadership 'at the top' to foster innovation across all levels of the organization (Bushe and Marshak 2016) 
Table 10.9 Dominant 'Achilles Heel' individual managerial skills for traveling NSMD influence pathways

\begin{tabular}{ll}
\hline Pathways & Training \\
\hline Direct & $\begin{array}{l}\text { Supply chain management: technological innovations for tracking (GIS, } \\
\text { remote sensing, data sharing) } \\
\text { Legal: knowledge of relevant countries' legal practices and procedures, } \\
\text { public policy legacies, and compliance and reporting requirements } \\
\text { Superseding }\end{array}$ \\
$\begin{array}{l}\text { International compliance: } \\
\text { operating procedures in relevant convention }\end{array}$ \\
$\begin{array}{l}\text { Hymbiotic } \\
\text { (legality verification) }\end{array}$
\end{tabular}

and the types of organizational forms that might nurture adaptive management (Laloux 2014).

These are clearly cross-cutting managerial capacities that any policy actor should master to effectively engage with colleagues and employees within the NSMD system and relevant government, intergovernmental arenas. However, whereas these skills are agnostic about particular organizational goals, NSMD certification systems were designed to address particular problems. This means that managerial skills must always be adjudicated for their ability to address these goals, rather than, as can inadvertently occur, maintaining the existence or growth of the system itself becoming the goal. When managerial and employee identities become focused on organizational reproduction rather than problem solving - such as direct and hybrid pathways being stuck in phase I - the entire NSMD project is threatened, which will serve to undermine legitimacy and authority and stakeholder support. As abilities to make these distinctions are the functions of political acumen and policy analytic capacity, it follows that these managerial functions must always be applied third in the sequence.

At the same time, we can also inductively identify 'Achilles Heel' 'micro level' management techniques that are different according to the pathway in question. For example, the direct pathway requires that managers understand, and can conduct, sophisticated supply chain management techniques that are taught in business schools and that take into account a range of technological innovations for creating efficient systems. Conversely, superseding pathways requires strong managerial training about relevant domestic countries legal requirements, often taught in law schools, through which diffusion must occur; while symbiotic requires knowledge of international treaty mechanisms and compliance management challenges, usually the domain of schools of global affairs and international relations. Given its complexity, it is unsurprising that the only pathway that does not have an Achilles Heel micro-management 
capacity building challenge is the Hybrid LV approach, in which all three micro capacities are key.

\section{CONCLUSION}

NSMD systems emerged a generation ago to address particular policy problems, such as deforestation, fisheries depletion, land degradation, and climate emissions. This chapter applied Howlett and Ramesh's framework to assess capacity challenges for these certification systems to, directly and indirectly, influence and address global and domestic public policy problems. This review highlights that the most significant capacity challenges for realizing their problem-solving potential is the ability to reflect on and theorize about forward thinking strategies and collaborations. Such a reorientation, as Bernstein et al. (2000) argued over a decade ago, challenges most empirical social science focused on explaining empirically measurable phenomena that have already occurred, to also focus on theorizing about the contingent empirical pathways on which we are embarked, and through which strategic interventions shape and influence pathways. This analysis has focused on the individual level capacity requirements. I recommend that future efforts apply the framework to identifying relevant organizational and system-wide capacities as well. One finding is clear: emphasis on managerial capacities at the expense of political acumen and policy analytic capacities does not just lead, as Kekez, Ramesh, and Howlett argue in the introduction, 'to a limited ability to anticipate collaborative governance failures,' but also leads to the inability to anticipate fully successful pathways and strategies for traveling them.

\section{NOTES}

1. I am grateful to the participants of the August 2017 Dubrovnik workshop on Collaborative Governance for their feedback, and especially Anka Kekez, Michael Howlett, and M Ramesh for detailed feedback. This review draws on a number of collaborative projects over the last 20 years, including the citations listed in the bibliography. I thank my collaborators over the years on public and private governance from which this review draws especially Kira Matas, Michael Stone, Michael Howlett, Steven Bernstein, Iben Nathan, Sophia Carodenuto, Sebastien Jodoin, Sina Leipold and Graeme Auld.

2. Eastern European countries and Russia are currently included in the 'developing country' category. 